\title{
Tratamento de dejetos de suinocultura em reator anaeróbio com pós-tratamento aeróbio/anóxico
}

\author{
Treatment of swine slurry in anaerobic \\ reactor with aerobic/anoxic post-treatment
}

Paulo Fernando Araújo Feitosa Leite', Daniele Vital Vich ${ }^{1 *} \odot$, Nélia Henriques Callado' $\odot$

\begin{abstract}
RESUMO
A suinocultura é caracterizada pela produção de grande volume de dejetos, que quando dispostos inadequadamente provocam impactos nos recursos hídricos, no solo e no ar, além de promoverem riscos à saúde humana. A remoção conjunta de matéria orgânica e nutrientes tem se mostrado um desafio para o tratamento desse tipo de resíduo. Diante disso, o presente estudo avaliou a remoção simultânea de matéria carbonácea, nitrogênio e fósforo presentes em dejetos de suinocultura, em um sistema de tratamento biológico composto de um reator anaeróbio de fluxo ascendente e manta de lodo (UASB), seguido de um reator em batelada sequencial (RBS) operado em ciclos aeróbio/anóxico de 24 h. O sistema foi dividido em duas etapas operacionais: coluna de sedimentação, UASB e RBS, e UASB e RBS. O reator UASB, com tempo de detenção hidráulica de 15,5 h e carga orgânica volumétrica aplicada de 5,5 kg DQO. $\mathrm{m}^{-3} \cdot \mathrm{d}^{-1}$, alcançou eficiência média de remoção de demanda química de oxigênio (DQO) de $84 \%$ na primeira etapa. Na Etapa 1, ocorreu o melhor desempenho do sistema, com eficiências médias globais de remoção de DQO, nitrogênio total e fósforo iguais a 78, 85 e 67\%, respectivamente.
\end{abstract}

Palavras-chave: tratamento anaeróbio-aeróbio; remoção biológica de nutrientes; dejetos de suinocultura.

\begin{abstract}
Swine farming is characterized by the production of a large volume of manure, which when improperly disposed causes impacts on water resources, soil, and air, in addition to promoting risks to human health. The joint removal of organic matter and nutrients from this type of waste has been a challenge. Therefore, the present study evaluated the simultaneous removal of carbonaceous matter, nitrogen, and phosphorus from swine wastewater in a biological treatment system composed of an upflow anaerobic sludge blanket reactor (UASB), followed by a sequential batch reactor (SBR) operated in 24 hours aerobic/anoxic cycles. The system was divided into two operational phases: Sedimentation Column, UASB and SBR, and UASB and SBR. The UASB reactor, with hydraulic retention time of $15.5 \mathrm{~h}$ and applied organic volumetric load of $5.5 \mathrm{~kg}$ COD. $\mathrm{m}^{-3} \cdot \mathrm{d}^{-1}$, achieved an average COD removal efficiency of $84 \%$ in the first stage. Stage 1 presented the best performance, with global average removal efficiencies of 78,85 , and $67 \%$ for COD, total nitrogen, and phosphorus, respectively.
\end{abstract}

Keywords: anaerobic-aerobic treatment; biological removal of nutrients; swine slurry.

\section{INTRODUÇÃO}

A suinocultura tornou-se uma atividade responsável por problemas ambientais em razão da produção excessiva de dejetos e da intensiva utilização de água de lavagem em propriedades com alta densidade populacional de suínos (KUNZ; MIELE; STEINMETZ, 2009; WANG et al., 2017; NAGARAJAN et al., 2019; RADHAKRISHNAN et al., 2019).

Os dejetos suínos, compostos da excreta dos animais, de água de lavagem e outros resíduos oriundos do sistema de criação são caracterizados por sua elevada concentração de matéria orgânica, nutrientes como nitrogênio $(\mathrm{N})$ e fósforo (P), presença de metais contidos na dieta dos animais e patógenos (OLIVEIRA;
FORESTI, 2004; KUNZ, 2006; WAKI et al., 2018; NAGARAJAN et al., 2019; RADHAKRISHNAN et al., 2019). A sua disposição inadequada provoca alterações na biodiversidade do ambiente aquático, diminuição do teor de oxigênio dissolvido (OD), eutrofização do corpo d'água, risco à saúde em razão do nitrato e dos microrganismos patogênicos presentes, e intoxicação de peixes e outros organismos devido à presença de amônia em sua forma livre (OBAJA et al., 2003; KUNZ, 2006; ABREU NETO; OLIVEIRA, 2009; RAJAGOPAL et al., 2011; NAGARAJAN et al., 2019; RADHAKRISHNAN et al., 2019).

Diante disso, tem-se intensificado a busca pelo desenvolvimento de tecnologias de tratamento desse dejeto, a fim de tornar a atividade suinícola ambientalmente

'Universidade Federal de Alagoas - Maceió (AL), Brasil.

*Autora correspondente: daniele.vich@ctec.ufal.br, danielevich@gmail.com

Conflitos de interesse: os autores declaram não haver conflito de interesses.

Financiamento: Coordenação de Aperfeiçoamento de Pessoal de Nível Superior (Capes), Conselho Nacional de Desenvolvimento Científico e Tecnológico (CNPq) e Fundação de Amparo à Pesquisa do Estado de Alagoas (Fapeal).

Recebido: 15/01/2O2O - Aceito: 26/06/2O2O - Reg. ABES: 20200009 
viável (KUNZ, 2006; DENG et al., 2008; NAGARAJAN et al., 2019). Entre as possibilidades de tratamento, a digestão anaeróbia tem sido amplamente utilizada, com destaque para os reatores anaeróbios de fluxo ascendente e manta de lodo (UASB), em razão da necessidade de menores áreas para sua implantação, de seu baixo custo de projeto e operação, da menor produção de lodo e da geração de metano (DENG; CAI; CHEN, 2007; CHERNICHARO, 2008; OLIVEIRA; SANTANA, 2011; RAJAGOPAL et al., 2011; SANTOS; MAYERLE; CAMPOS, 2014). No entanto, esses reatores apresentam baixo desempenho na remoção de nutrientes, gerando um efluente com elevada concentração de nitrogênio amoniacal - N-amoniacal (OBAJA et al., 2003; DENG; CAI; CHEN, 2007; RAJAGOPAL et al., 2011).

Visando à remoção de $\mathrm{N}$ e $\mathrm{P}$, além da remoção complementar de matéria orgânica, o reator em batelada sequencial (RBS) tem sido estudado para o pós-tratamento dos dejetos de suinocultura (DENG et al., 2008). O uso do RBS permite estabelecer condições de processo que promovam a remoção biológica de nutrientes graças à flexibilidade das etapas de um ciclo de operação (CALLADO, 2001; CHERNICHARO, 2001; OLIVEIRA; SANTANA, 2011).

Entretanto, ao utilizar um RBS no tratamento de um efluente digerido, Deng et al. (2008) alcançaram baixas eficiências de remoção de demanda química de oxigênio (DQO), $\mathrm{N}$-amoniacal e P. Os autores atribuíram esse inconveniente ao déficit de matéria orgânica para a desnitrificação, não havendo, nessa etapa, a compensação da alcalinidade consumida na nitrificação, ocasionando redução do potencial hidrogeniônico $(\mathrm{pH})$ e mau funcionamento do processo aeróbio.

Yang et al. (2016) propuseram a distribuição desequilibrada da massa poluente e dos volumes de efluentes como solução desse problema. O estudo fez uso de uma coluna de sedimentação (CS) para separar os dejetos de suinocultura em líquido de alta concentração (LAC) e líquido de baixa concentração (LBC) em diferentes razões de separação. O primeiro líquido, após ser digerido anaerobiamente, era misturado com o segundo e encaminhado para o tratamento aerado. Os autores obtiveram eficiências de remoção de 97\% para DQO, 99\% para $\mathrm{N}$-amoniacal, $92 \%$ para nitrogênio total (NT) e $75 \%$ para fósforo total.

Com base nos bons resultados obtidos, o presente estudo avaliou o tratamento de dejetos de suinocultura em um sistema de tratamento biológico, composto de reator anaeróbio tipo UASB seguido de RBS operado em ciclos aeróbio/anóxico, para remoção simultânea da matéria carbonácea, do $\mathrm{N}$ e do $\mathrm{P}$.

\section{METODOLOGIA}

Para a execução da presente pesquisa, os dejetos de suinocultura foram coletados em uma granja de suínos de ciclo completo, com os animais separados por fases do ciclo de vida (maternidade, crescimento e terminação), localizada no município de Viçosa, Zona da Mata de Alagoas, a 93 km de Maceió, a capital do estado. A coleta ocorreu na descarga da lâmina d'água nas baias de confinamento, após a homogeneização do resíduo presente na lâmina. Logo após, houve peneiramento dos dejetos em duas etapas, variando a abertura da malha da peneira de 3 a $1 \mathrm{~mm}$. Essa medida foi tomada com o objetivo de promover um tratamento preliminar antes de seu armazenamento, para remoção dos sólidos mais grosseiros, de modo a evitar danos ao sistema.

Em seguida, as amostras foram transportadas para o Laboratório de Saneamento Ambiental (LSA) do Centro de Tecnologia (CTEC) da Universidade Federal de Alagoas (Ufal), onde a instalação experimental foi montada, e procederam-se as análises físico-químicas e o acondicionamento em freezer $-20^{\circ} \mathrm{C}$ para garantir a uniformidade em sua composição.

O tratamento e o pós-tratamento dos dejetos de suinocultura foram realizados em um reator UASB e um RBS, ambos em escala de bancada. O desenvolvimento desta pesquisa foi dividido em duas etapas. Na Etapa 1, com duração de 22 dias, o tratamento ocorreu em um sistema composto de CS, reator UASB e RBS (Figura 1A). Na Etapa 2, houve a retirada da CS, e o tratamento ocorreu no reator UASB seguido do RBS durante 41 dias (Figura 1B).

A CS utilizada foi confeccionada em acrílico com $14,5 \mathrm{~cm}$ de diâmetro, $54 \mathrm{~cm}$ de altura, volume total de $9 \mathrm{~L}$ e volume útil de 8,25 L. Antes do experimento, foi desenhada uma linha divisória na coluna de decantação a $22 \mathrm{~cm}$ do fundo, para assegurar uma relação entre LAC e LBC (v/v) de 4:6. No que diz respeito à operação, o dejeto bruto era colocado no reservatório R1, que por gravidade alimentava a CS para separação do dejeto na relação pretendida (Figura 1A). Após 3 h de sedimentação (YANG et al., 2016), o sobrenadante acima da linha divisória (LBC) e o sedimento abaixo da linha divisória (LAC) eram descartados em dois reservatórios distintos, R2 e R3, respectivamente, para análise e envio ao tratamento nas unidades subsequentes.

O reator UASB utilizado foi construído em acrílico com $70 \mathrm{~cm}$ de altura, $8 \mathrm{~cm}$ de diâmetro interno na zona de digestão (parte inferior) e $14 \mathrm{~cm} \mathrm{na}$ zona de sedimentação (parte superior), obtendo-se assim aproximadamente 4,65 L de volume total. Foi instalada uma bomba peristáltica para alimentação do reator, que foi operado de forma contínua, sendo alimentado na Etapa 1 com o LAC contido no R4 (Figura 1A), com uma recirculação, e na Etapa 2 com o dejeto bruto contido no R1 (Figura 1B). A vazão de alimentação foi de 0,30 L.h $\mathrm{h}^{-1}$, correspondendo assim a um tempo de detenção hidráulica (TDH) de 15,5 h e carregamento hidráulico volumétrico $(\mathrm{CHV})$ de $1,55 \mathrm{~m}^{3} \cdot \mathrm{m}^{-3} \cdot \mathrm{d}^{-1}$. A finalidade desse reator foi remover a maior fração de matéria orgânica e promover a amonificação.

O RBS utilizado foi construído em acrílico com $14,5 \mathrm{~cm}$ de diâmetro, $54 \mathrm{~cm}$ de altura e volume útil de 8 L. No RBS, foi instalado um soprador de ar, conectado por meio de mangueiras de borracha a quatro pedras porosas no fundo do reator, para fornecer ar ao sistema (fase aeróbia), e uma bomba peristáltica para a recirculação do efluente em seu interior (fase anóxica). O acionamento e o desligamento tanto da bomba de recirculação quanto do aerador eram executados por meio de dois temporizadores analógicos previamente programados de acordo com o período de cada fase do ciclo operacional.

O RBS operou em ciclos de $24 \mathrm{~h}$ (Tabela 1), sob condições alternadas aeróbia/anóxica, sendo alimentado na Etapa 1 com líquido misto com volume composto de $40 \%$ do efluente do UASB e $60 \%$ do LBC, contido no R5 (Figura 1A). Já na Etapa 2, o reator foi alimentado por meio do R3 com o efluente do UASB (Figura 1B). O RBS teve a finalidade de remover a matéria orgânica remanescente, realizar a nitrificação, a remoção biológica de $\mathrm{P}$ e a desnitrificação.

No início da fase anóxica, havia adição de fonte externa de carbono C (metanol) para remoção biológica de P e desnitrificação. A quantidade de metanol adicionado $(11 \mathrm{~mL})$ foi calculada em função da concentração média de nitrato da fase anterior potencialmente disponível para a desnitrificação, com relação teórica C/N de 1,1 (CALLADO, 2001). Além disso, era adicionado bicarbonato de sódio ao afluente $\left(2.000 \mathrm{mg} \cdot \mathrm{L}^{-1}\right)$ para aumento da alcalinidade.

Para inocular o reator anaeróbio, utilizou-se $0,85 \mathrm{~L}$ de lodo coletado de um RBS com ciclos anaeróbios em escala de bancada, tratando esgoto sanitário 
A

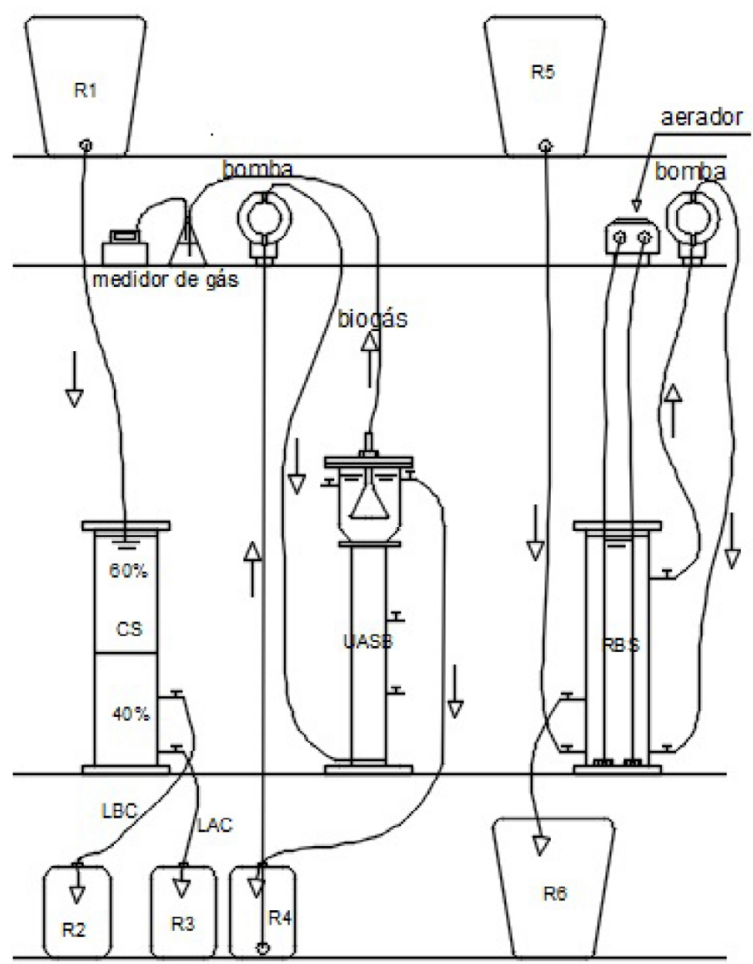

B

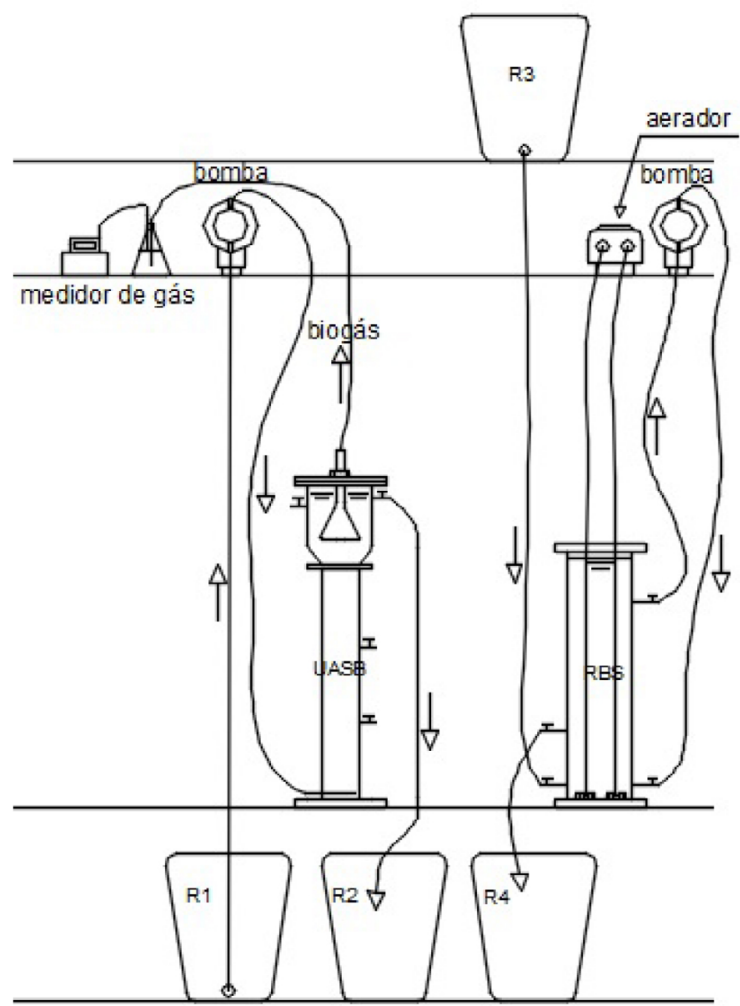

CS: coluna de sedimentação; LAC: líquido de alta concentração; LBC: líquido de baixa concentração; UASB: reator anaeróbio de fluxo ascendente e manta de lodo: RBS: reator em batelada sequencial; R1: reservatório com dejeto suíno bruto; R2: reservatório com LBC; R3: reservatório com LAC; R4: reservatório com LAC e efluente do reator UASB; R5: reservatório com líquido misto; R6: reservatório com efluente do RBS.

Figura 1 - Esquema da instalação experimental utilizada nas etapas (A) 1 e (B) 2.

Tabela 1 - Tempo de duração dos períodos do ciclo operacional do reator em batelada sequencial.

\begin{tabular}{|c|c|c|}
\hline \multicolumn{2}{|c|}{ Período do ciclo } & Duração \\
\hline \multicolumn{2}{|c|}{ Enchimento } & $0,25 \mathrm{~h}$ \\
\hline \multirow{5}{*}{ Reação } & Aeróbia & $14 \mathrm{~h}$ \\
\hline & Sedimentação & $0,5 \mathrm{~h}$ \\
\hline & Anóxica & $3 \mathrm{~h}$ \\
\hline & Fonte externa de carbono & $1.448,3$ mg metanol.L-1 \\
\hline & Aeróbia & $2,5 \mathrm{~h}$ \\
\hline \multicolumn{2}{|c|}{ Sedimentação } & $3,5 \mathrm{~h}$ \\
\hline \multicolumn{2}{|c|}{ Descarte } & $0,25 \mathrm{~h}$ \\
\hline
\end{tabular}

sintético, oriundo de outra pesquisa desenvolvida no CTEC/Ufal. Da mesma pesquisa, para inoculação do RBS, foram utilizados $2 \mathrm{~L}$ de lodo proveniente de um RBS com ciclos aeróbio/anóxico. Os lodos utilizados não foram submetidos a nenhum processo de adaptação ou tratamento antes da inoculação.

Duas vezes por semana, foram coletadas amostras do afluente e dos efluentes da CS e dos efluentes do UASB e do RBS. Para o monitoramento do sistema, determinou-se: DQO, nitrogênio total Kjeldahl (NTK), $\mathrm{N}$-amoniacal $\left(\mathrm{N}_{-} \mathrm{NH}_{4}^{+}\right)$,
$\mathrm{P}\left(\mathrm{P}-\mathrm{PO}_{4}{ }^{3-}\right)$, sólidos voláteis totais (SVT) e sólidos totais (ST), de acordo com o Standard Methods for Examination of Water and Wastewater (APHA, 2017).

As análises de nitrato e nitrito foram realizadas segundo Mackereth, Heron e Talling (1978). Para a análise de alcalinidade total (AT), alcalinidade intermediária (AI) e a alcalinidade parcial (AP), utilizou-se o método titulométrico modificado por Ripley, Boyle e Converse (1986). O OD foi determinado com o uso de um oxímetro da marca ALFAKIT modelo AT 160. O pH foi medido pelo método potenciométrico.

\section{RESULTADOS E DISCUSSÃO}

Durante todo o período da pesquisa (64 dias), o sistema operou à temperatura ambiente oscilando entre 30 e $33,5^{\circ} \mathrm{C}$, com média de $31,5^{\circ} \mathrm{C}$. Observa-se que a operação do sistema ocorreu dentro da faixa de 25 a $40^{\circ} \mathrm{C}$, classificada como mesofílica (VON SPERLING, 2014). Essa faixa de temperatura é ideal para favorecer a atividade bacteriana e promover a ocorrência das reações químicas de interesse deste estudo, como a oxidação de matéria orgânica e a remoção de nutrientes (METCALF; EDDY, 2016).

Em relação à matéria orgânica, é possível observar na Figura 2A que o reator UASB se adaptou bem ao dejeto de suinocultura, suportando as grandes variações na concentração de DQO afluente na Etapa 1, apresentando 


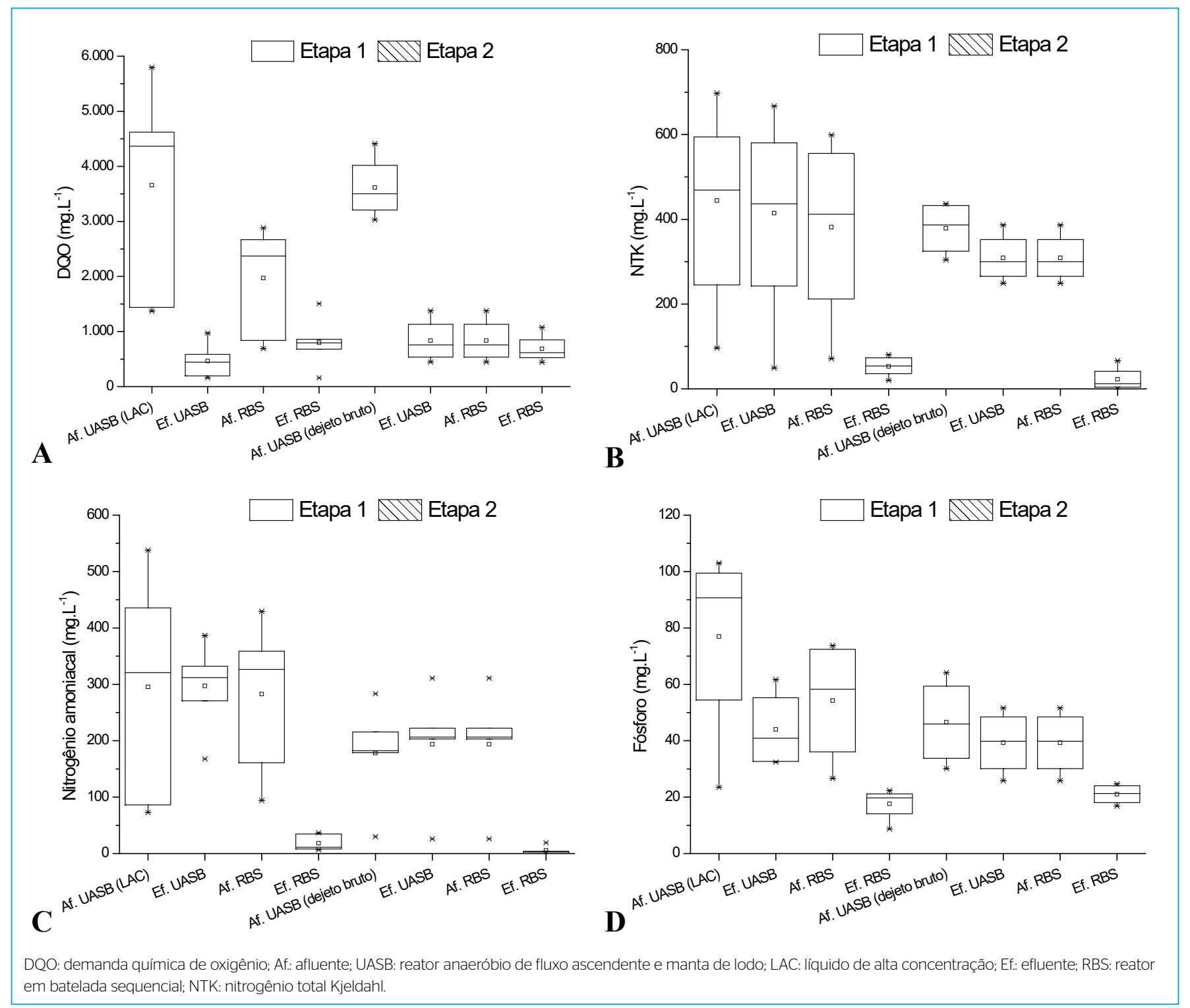

Figura 2 - Concentrações de (A) demanda química de oxigênio, (B) nitrogênio total Kjeldahl, (C) nitrogênio amoniacal e (D) fósforo na Etapa 1 (afluente UASB-LAC, efluente UASB, afluente RBS e efluente RBS) e na Etapa 2 (afluente UASB-dejeto bruto, efluente UASB/afluente RBS e efluente RBS).

concentrações de DQO próximas a $500 \mathrm{mg} . \mathrm{L}^{-1}$ no efluente. O RBS teve comportamento semelhante nessa primeira etapa, tendo um efluente com concentrações de DQO sem grandes variações, próximas à média de $800 \mathrm{mg} \cdot \mathrm{L}^{-1}$. $\mathrm{Na}$ segunda etapa, observou-se pouca dispersão das concentrações afluente e efluente do RBS.

No que diz respeito à remoção de matéria orgânica (Tabela 2), durante a Etapa 1, os resultados obtidos mostraram no reator UASB uma concentração média de DQO no afluente e no efluente, respectivamente, de 3.660 e $466 \mathrm{mg} . \mathrm{L}^{-1}$, com eficiência média de remoção de $84 \%$. Já na Etapa 2, quando o UASB passou a ser alimentado diretamente com o dejeto bruto, essa eficiência de remoção diminuiu para $76 \%$, apresentando afluente e efluente com valores médios de 3.613 e 834 mg..$^{-1}$, respectivamente.

Ao tratar dejetos de suinocultura utilizando reator UASB de bancada com TDH de 8 a 30 h, Kalyuzhnyl e Sklyar (2000) obtiveram eficiência de remoção de DQO de 60 a 85\%. Já Oliveira e Santana (2011) avaliaram o desempenho de dois reatores UASB em escala piloto para o tratamento de dejetos de suinocultura, aplicando taxas de carregamento orgânico volumétrico (COV) de 14,8 a $24,4 \mathrm{~kg}$ DQO. $\mathrm{m}^{-3} \cdot \mathrm{d}^{-1}$ e TDH de 28 e $11 \mathrm{~h}$ e de 14 e $6 \mathrm{~h}$, no primeiro e segundo reator, respectivamente. Os autores relataram eficiências médias de remoção de DQO entre 53 e 88\%. Chernicharo (2007) sugere uma remoção de matéria orgânica superior a $65 \%$ para um sistema anaeróbio ser considerado eficiente no tratamento de águas residuárias. Neste estudo, eficiências superiores a $75 \%$ foram obtidas nas duas etapas experimentais.

Oliveira e Foresti (2004) utilizaram reatores UASB de bancada para tratar dejetos de suinocultura e alcançaram eficiência de remoção de DQO total de $84 \%$ aplicando um COV de 5,72 kg DQO. $\mathrm{m}^{-3} \cdot \mathrm{d}^{-1}$, com TDH de $12 \mathrm{~h}$. No presente estudo, com COV (5,5 kg DQO.m $\left.\mathrm{m}^{-3} \cdot \mathrm{d}^{-1}\right)$ e TDH $(15,5 \mathrm{~h})$ semelhantes, alcançou-se, na Etapa 1, a mesma eficiência de remoção de DQO. 
Tabela 2 - Valores médios de demanda química de oxigênio, sólidos totais e sólidos voláteis obtidos durante a operação do sistema.

\begin{tabular}{|c|c|c|c|}
\hline \multicolumn{2}{|c|}{ Parâmetros } & Etapa 1 & Etapa 2 \\
\hline \multirow{6}{*}{$\mathrm{DQO}\left(\mathrm{mg} \cdot \mathrm{L}^{-1}\right)$} & Dejeto suíno bruto & & $3.613 \pm 587$ \\
\hline & LAC & $3.660 \pm 901$ & \\
\hline & LBC & $2.975 \pm 1.501$ & \\
\hline & Ef. UASB & $466 \pm 298$ & \multirow{2}{*}{$834 \pm 405$} \\
\hline & Af. RBS & $1.971 \pm 956$ & \\
\hline & Ef. RBS & $799 \pm 431$ & $688 \pm 274$ \\
\hline \multirow{6}{*}{$\mathrm{ST}\left(\mathrm{mg} \cdot \mathrm{L}^{-1}\right)$} & Dejeto suíno bruto & & $3.085 \pm 18$ \\
\hline & LAC & $5.321 \pm 1.899$ & \\
\hline & LBC & $4.330 \pm 4.366$ & \\
\hline & Ef. UASB & $1.083 \pm 396$ & \multirow{2}{*}{$1.508 \pm 17$} \\
\hline & Af. RBS & $3.031 \pm 2.461$ & \\
\hline & Ef. RBS & $2.908 \pm 691$ & $2.525 \pm 5$ \\
\hline \multirow{6}{*}{$\mathrm{SVT}\left(\mathrm{mg} \cdot \mathrm{L}^{-1}\right)$} & Dejeto suíno bruto & & $1.600 \pm 25$ \\
\hline & LAC & $2.912 \pm 963$ & \\
\hline & LBC & $2.250 \pm 2.127$ & \\
\hline & Ef. UASB & $390 \pm 306$ & \multirow{2}{*}{$432 \pm 11$} \\
\hline & Af. RBS & $1.505 \pm 1.154$ & \\
\hline & Ef. RBS & $532 \pm 214$ & $472 \pm 21$ \\
\hline
\end{tabular}

DQO: demanda química de oxigênio; ST: sólidos totais; SVT: sólidos voláteis totais; LAC: líquido de alta concentração; LBC: líquido de baixa concentração; Ef.: efluente; UASB: reator anaeróbio de fluxo ascendente e manta de lodo; Af: afluente; RBS: reator em batelada sequencial.

Já no RBS, as concentrações médias de DQO afluente e efluente para as etapas 1 e 2 foram, respectivamente, 1.971 e $799 \mathrm{mg} . \mathrm{L}^{-1}$ e 834 e $688 \mathrm{mg} . \mathrm{L}^{-1}$ (Tabela 2). Ressalta-se que na primeira etapa o RBS tinha como afluente a mistura entre o efluente do UASB e o LBC a uma razão de 4:6. Mesmo com concentração média afluente menor que a da etapa anterior, a eficiência média de remoção de DQO na Etapa 2 foi em torno de 6\%, sendo significativamente inferior ao percentual registrado na primeira etapa (58\%). Tal fato é explicado em razão de a alimentação do RBS na segunda etapa ter sido realizada apenas com o efluente digerido no reator UASB, em que ocorria a degradação da fração mais facilmente biodegradável da matéria orgânica, ficando a fração recalcitrante para ser degradada no RBS.

A influência das distribuições desequilibradas da massa poluente e dos volumes no tratamento de águas residuárias da suinocultura foi estudada por Yang et al. (2016). Utilizando um RBS com ciclo operacional de $12 \mathrm{~h}$ e um TDH de 5 dias na etapa aeróbia da sua pesquisa, os autores alcançaram, no sistema com razão de separação de volumes de 3:7, eficiência média de remoção de DQO de 56,9\%, com concentração de DQO afluente de $3.281 \mathrm{mg} \cdot \mathrm{L}^{-1}$. Tal resultado se assemelha à eficiência média obtida na Etapa 1 do presente estudo.

Os resultados encontrados na Etapa 2 do presente estudo corroboram com Wang et al. (2017). Segundo os autores, a maioria dos trabalhos que utilizaram RBS para tratamento de efluentes digeridos diretamente, apresentou desempenho muito baixo, com remoção de 10 a $60 \%$ de DQO. Em seu estudo, foram utilizados três RBS com TDH variando de 1,25 a 12,5 dias, com concentração de DQO afluente de 540 e 643 mg.L $\mathrm{L}^{-1}$, obtendo eficiências médias de remoção de DQO variando de 8,80 a $22,10 \%$.

Diante do exposto, o reator UASB apresentou desempenho na remoção de matéria orgânica satisfatório nas duas etapas, sendo compatível com o tipo de tratamento e com eficiências de remoção iguais ou superiores a valores encontrados na literatura. Porém, o RBS apresentou baixo desempenho na remoção de DQO remanescente, prejudicando as eficiências de remoção global do sistema, que foram de $78 \%$ na Etapa 1, aumentando para $81 \%$ na Etapa 2. Esse último valor, por exemplo, aproxima-se dos $86,90 \%$ alcançados por Deng et al. (2008) tratando diretamente águas residuárias da suinocultura em um sistema composto de reator UASB seguido de RBS aeróbio.

Como pode ser visto na Tabela 2, nas duas etapas operacionais do reator UASB, os valores médios de sólidos totais e voláteis no efluente foram inferiores aos do afluente, apontando a retenção de sólidos. As concentrações médias de ST e SVT do afluente foram de 5.321 e $2.912 \mathrm{mg} . \mathrm{L}^{-1}$ e de 3.085 e $1.600 \mathrm{mg} . \mathrm{L}^{-1}$, nas etapas 1 e 2 , respectivamente. Como já esperado, verificaram-se valores maiores nos afluentes da primeira etapa em razão da alimentação do reator nessa etapa com a fração de dejetos suínos sedimentada na CS (LAC). As relações SVT/ST de 0,55 e 0,52, respectivamente, indicam a predominância dos sólidos orgânicos.

Os valores médios de ST e SVT no efluente do UASB diminuíram para 1.083 e 390 mg.L $L^{-1}$, e para 1.508 e 432 mg.L.-1 , nas etapas 1 e 2, respectivamente (Tabela 2). É possível verificar a predominância dos sólidos fixos, diferentemente do afluente. Diante disso, as eficiências médias de remoção de ST e SVT foram, respectivamente, de 80 e 87\%, na Etapa 1, e diminuíram para 51 e 73\%, na Etapa 2.

No RBS, na Etapa 1, registrou-se uma eficiência de remoção de apenas $4 \%$ para ST e 65\% para SVT, com concentrações médias efluentes de 2.908 e $532 \mathrm{mg} . \mathrm{L}^{-1}$, indicando que $18 \%$ dos ST no efluente eram sólidos orgânicos. Já na Etapa 2, os valores médios de ST e SVT, respectivamente, aumentaram de 1.508 e $432 \mathrm{mg} . \mathrm{L}^{-1}$, no afluente, para 2.525 e $472 \mathrm{mg} . \mathrm{L}^{-1}$, no efluente (Tabela 2). Desse modo, nota-se que houve arraste de sólidos no RBS, inclusive, sendo refletido nos valores de DQO, uma vez que em dois ciclos foi observada concentração de DQO efluente maior que a afluente. No efluente, foi possível verificar a predominância dos sólidos fixos, pois a relação SVT/ST foi em torno de 0,19 . Vale ressaltar que, nessa etapa, o RBS foi alimentado diretamente com o efluente do reator UASB, ou seja, boa parte dos sólidos foram removidos durante o tratamento anaeróbio.

As concentrações médias de NTK e N-amoniacal nas etapas 1 e 2 da presente pesquisa podem ser visualizadas nas Figuras 2B e 2C. Já as concentrações médias de $\mathrm{P}$ podem ser visualizadas na Figura 2D. No que diz respeito aos compostos nitrogenados (Tabela 3), no reator UASB, durante a Etapa 1, o NTK $\left({\mathrm{N}-\mathrm{NH}_{4}}_{4}+\mathrm{N}-\mathrm{Org}\right.$.) apresentou concentrações médias de 503 e $475 \mathrm{mg} . \mathrm{L}^{-1}$, respectivamente, no afluente e no efluente. Em média $41 \%$ da concentração afluente estava na forma orgânica e 59\%, na forma amoniacal. Já no efluente, em torno de $37 \%$ do NTK estava na forma de N-Org., apontando que apenas $29 \mathrm{mg} . \mathrm{L}^{-1}$ foram amonificados, representando eficiência média de amonificação de $14 \%$. No entanto, os valores de $\mathrm{N}$-amoniacal afluente e efluente do UASB foram, respectivamente, 296 e $297 \mathrm{mg} . \mathrm{L}^{-1}$ (Tabela 3), ou seja, houve acréscimo de apenas $1 \mathrm{mg} . \mathrm{L}^{-1}$ de $\mathrm{N}$ na forma amoniacal, inferior aos $29 \mathrm{mg} . \mathrm{L}^{-1}$ de N amonificado. Diante disso, verificou-se eficiência média de remoção de NT de $6 \%$ no reator UASB.

Como esperado, em razão da alimentação direta do reator UASB com o dejeto bruto, na Etapa 2 a concentração média afluente de NTK, no valor de $379 \mathrm{mg} . \mathrm{L}^{-1}$, foi consideravelmente inferior ao verificado na Etapa 1. Além disso, 
Tabela 3 - Concentração média dos compostos nitrogenados no sistema.

\begin{tabular}{|c|c|c|c|}
\hline \multicolumn{2}{|c|}{ Parâmetros } & Etapa 1 & Etapa 2 \\
\hline \multirow{6}{*}{ NTK (mg.L-1) } & Dejeto suíno bruto & & $379 \pm 65$ \\
\hline & LAC & $503 \pm 156$ & \\
\hline & LBC & $405 \pm 184$ & \\
\hline & Ef. UASB & $475 \pm 154$ & \multirow{2}{*}{$309 \pm 59$} \\
\hline & Af. RBS & $433 \pm 163$ & \\
\hline & Ef. RBS & $60 \pm 19$ & $23 \pm 30$ \\
\hline \multirow{6}{*}{ N-Org. (mg. $\left.L^{-1}\right)$} & Dejeto suíno bruto & & $164 \pm 87$ \\
\hline & LAC & $207 \pm 125$ & \\
\hline & LBC & $132 \pm 50$ & \\
\hline & Ef. UASB & $178 \pm 124$ & \multirow{2}{*}{$73 \pm 77$} \\
\hline & Af. RBS & $150 \pm 58$ & \\
\hline & Ef. RBS & $42 \pm 26$ & $21 \pm 28$ \\
\hline \multirow{6}{*}{$\mathrm{N}-\mathrm{NH}_{4}\left(\mathrm{mg} \cdot \mathrm{L}^{-1}\right)$} & Dejeto suíno bruto & & $215 \pm 48$ \\
\hline & LAC & $296 \pm 187$ & \\
\hline & LBC & $273 \pm 182$ & \\
\hline & Ef. UASB & $297 \pm 74$ & \multirow{2}{*}{$236 \pm 51$} \\
\hline & Af. RBS & $283 \pm 129$ & \\
\hline & Ef. RBS & $18 \pm 14$ & $2 \pm 2$ \\
\hline $\mathrm{N}-\mathrm{NO}_{2}\left(\mathrm{mg} \cdot \mathrm{L}^{-1}\right)$ & RBS & $0,207 \pm 0,3$ & $1,025 \pm 0,6$ \\
\hline $\mathrm{N}-\mathrm{NO}_{3}\left(\mathrm{mg} \cdot \mathrm{L}^{-1}\right)$ & RBS & $20 \pm 16$ & $48 \pm 45$ \\
\hline $\mathrm{OD}\left(\mathrm{mg} . \mathrm{L}^{-1}\right)$ & RBS & 4,4 & 5,1 \\
\hline
\end{tabular}

NTK: nitrogênio total Kjeldahl; OD: oxigênio dissolvido; LAC: líquido de alta concentração; LBC: líquido de baixa concentração; Ef: efluente; UASB: reator anaeróbio de fluxo ascendente e manta de lodo; Af: afluente; RBS: reator em batelada sequencial.

aproximadamente $44 \%$ do afluente estava na forma orgânica e o efluente apresentou concentração média de $309 \mathrm{mg} . \mathrm{L}^{-1}$, o que significa eficiência média de remoção de NT em torno de 19\%. Observou-se fração amonificada de $91 \mathrm{mg} \cdot \mathrm{L}^{-1}$, havendo conversão média de quase $56 \%$ de $\mathrm{N}$ orgânico a $\mathrm{N}$-amoniacal nessa etapa, sendo 42 pontos percentuais a mais que o registrado na etapa anterior.

As concentrações médias afluente e efluente de $\mathrm{N}$-amoniacal no reator UASB na Etapa 2 foram, respectivamente, 215 e $236 \mathrm{mg} . \mathrm{L}^{-1}$ (correspondente a $76 \%$ do NTK efluente). Assim, é possível constatar que concomitantemente ao aumento da eficiência de amonificação, houve incremento na porcentagem de NT removido no reator.

Oliveira e Santana (2011) indicam em seu estudo que os mecanismos de sedimentação e interceptação na manta de lodo estão relacionados com a redução de $\mathrm{N}$ orgânico no efluente dos reatores anaeróbios. Os autores demonstraram que a diminuição do TDH provoca queda nas remoções de NTK e N orgânico. Deng et al. (2008), tratando dejetos suínos com concentração média de NT de 997 mg.L-1 em um reator UASB, com TDH quase 5 vezes maior que o do presente estudo (3 dias), alcançaram eficiência de remoção de NT (19,60\%) similar à encontrada na Etapa 2.

Verifica-se que a diferença entre as concentrações afluente e efluente, que implicaram as eficiências de remoção de NT, são justamente as parcelas de N-Org. amonificado no reator UASB que não foram observadas nas concentrações de $\mathrm{N}$-amoniacal no efluente. Alguns autores explicam que essa parcela restante de $\mathrm{N}$-amoniacal produzido pode ter sido assimilada pelos microrganismos, removida pela sedimentação do amônio com a fração particulada dos dejetos e/ou ainda ter contribuído, junto com o fosfato e o magnésio, para a formação de estruvita $\left(\mathrm{MgNH}_{4} \mathrm{PO}_{4} \cdot 6 \mathrm{H}_{2} \mathrm{O}\right)$ (DOS SANTOS et al., 2007; DENG et al., 2008; SOUZA et al., 2016).

Os valores médios de NTK no efluente do RBS decresceram de 60 para $23 \mathrm{mg} . \mathrm{L}^{-1}$ nas etapas 1 e 2, respectivamente, resultando em redução de $86 \%$ do NTK afluente na primeira etapa, apresentando aumento na etapa seguinte, que teve eficiência média de remoção de $92 \%$ (Tabela 3). Foi possível observar que o processo de amonificação ocorreu durante a operação do RBS, havendo eficiência média de remoção de N-Org. similares nas duas etapas estudadas: 72 e $71 \%$, respectivamente.

As concentrações médias de $\mathrm{N}$-amoniacal no efluente do RBS foram de 18 mg.L.-1 na Etapa 1 e de apenas 2 mg.L-1 na Etapa 2 (Tabela 3). Diante do exposto, observando os valores médios no afluente, verifica-se o aumento da atividade nitrificante da Etapa 1 para a 2 durante a operação do RBS, com remoções médias crescentes de $\mathrm{N}-\mathrm{NH}_{4}$ de 93 e 99\%, respectivamente. Tais concentrações atendem ao padrão de lançamento de efluentes estabelecido na Resolução 430 do Conselho Nacional de Meio Ambiente (CONAMA) para esse parâmetro, que é de 20 mg.L.L (BRASIL, 2011).

O OD é um parâmetro importante que necessita de controle nos sistemas de remoção de N. No presente estudo, as concentrações médias desse parâmetro no RBS estiveram entre 4,4 e 5,1 mg. $\mathrm{L}^{-1}$ na etapa aeróbia, estando acima da concentração mínima de OD citada por Van Haandel e Marais (1999) para que ocorra nitrificação $\left(2 \mathrm{mg} \cdot \mathrm{L}^{-1}\right)$. Ainda segundo os autores, o tamanho dos flocos, a temperatura, a intensidade de agitação e, sobretudo, a taxa de consumo de oxigênio são fatores que interferem na concentração mínima de oxigênio necessária no interior do reator para a manutenção de um ambiente propício para os microrganismos responsáveis pelo processo.

Como pode ser visto na Tabela 3 , as concentrações de NT (NTK $+{\mathrm{N}-\mathrm{NO}_{2}}_{2}$ $+\mathrm{N}^{-\mathrm{NO}_{3}}{ }_{3}$ ) no efluente do RBS foram de 80,21 e 72,03 mg. $\mathrm{L}^{-1}$ para as etapas 1 e 2 , respectivamente, sendo inferiores aos valores afluentes de 433 e $309 \mathrm{mg} . \mathrm{L}^{-1}$, tendo como resultado eficiências médias de remoção de 82 e 77\%.

Esse desempenho alcançado na remoção de NT no RBS foi semelhante e superior ao relatado por Waki et al. (2018) em seu estudo com dois sistemas de lodos ativados tratando dejetos de suinocultura, com valor médio de NT afluente de $720 \mathrm{mg} . \mathrm{L}^{-1}$, sob alta $\left(1,7\right.$ a 2,6 mg.L $\left.\mathrm{L}^{-1}\right)$ e baixa $\left(<0,1 \mathrm{mg} . \mathrm{L}^{-1}\right)$ concentração de OD. No sistema com maior concentração de OD, as eficiências de remoção de NT atingidas foram de 12, 24 e 46\%, enquanto na menor concentração foi de 64,89 e $88 \%$ para 10,20 e $30^{\circ} \mathrm{C}$, respectivamente. Os autores justificaram que a melhor remoção de NT nas menores concentrações de OD ocorreram em razão da nitrificação e desnitrificação simultâneas.

O efluente do RBS apresentou concentração média de nitrito de 0,207 mg. $\mathrm{L}^{-1}$ na Etapa 1, aumentando na Etapa 2 para 1,025 mg.L-1 (Tabela 3). Em relação ao nitrato (Tabela 3), também houve aumento nas concentrações médias efluentes no RBS da Etapa 1 para a 2, registrando-se 20 e $48 \mathrm{mg} . \mathrm{L}^{-1}$, respectivamente. Diante dos valores médios de nitrito bastante inferiores aos de nitrato, pode-se assegurar que houve condições ambientais propícias para a oxidação de maior parte do $\mathrm{N}$-amoniacal à nitrato durante a operação do reator.

Diante dos valores médios de nitrito e nitrato no efluente e as concentrações de NT removidas no RBS, verifica-se a ocorrência do processo de desnitrificação no reator com eficiências médias de $95 \%$ na primeira etapa e decrescendo para $83 \%$ na segunda, mesmo com a adição da mesma fonte de $\mathrm{C}$, o que sugere a 
influência do afluente utilizado, que deixou de ser o líquido misto (LBC + efluente UASB) e passou a ser diretamente o efluente digerido no reator UASB. As relações $\mathrm{C} / \mathrm{N}$ encontradas com o uso de metanol como fonte externa de $\mathrm{C}$ foram de 1,5 e $2,3 \mathrm{mg} \mathrm{C}\left(\mathrm{mg} \mathrm{N}_{\text {reduzido }}\right)^{-1}$, respectivamente, para as etapas 1 e 2, estando na faixa trabalhada por Callado (2001), também utilizando metanol, de 1,1 a 3,2.

O RBS apresentou eficiências de remoção de NT, NTK e N-amoniacal durante as etapas estudadas iguais e/ou maiores que as encontradas por Oliveira e Santana (2011), que avaliaram um RBS tratando diretamente efluentes de reatores UASB em dois estágios com valores médios de NT igual a NTK, de 384 a 505 mg. $\mathrm{L}^{-1}$, e $\mathrm{N}$-am de 202 a $320 \mathrm{mg} . \mathrm{L}^{-1}$, e que alcançaram eficiências de remoção para esses parâmetros variando de 58 a 68\%, 69 a 83\% e 89 a 96\%, respectivamente.

Já analisando a remoção dos compostos nitrogenados no sistema estudado, as eficiências médias global para NT, NTK e N-amoniacal foram, respectivamente, 85, 87 e 95\% na Etapa 1, e 81, 94 e 99\% na Etapa 2. Essas eficiências obtidas foram semelhantes às encontradas por Yang et al. (2016): 86 a 99\% para $\mathrm{N}$-amoniacal e 80 a $94 \%$ para NT, utilizando dois RBS em um sistema combinado anaeróbio-aeróbio, também com base na distribuição desequilibrada da massa poluente e dos volumes de dejetos suínos.

De acordo com Chernicharo (2008), parâmetros como pH, alcalinidade e concentração de ácidos voláteis são estreitamente relacionados e de grande importância para o controle e a operação adequada de reatores anaeróbios. No reator UASB, durante a Etapa 1, os valores de $\mathrm{pH}$ afluente (LAC) e efluente (Figura 3) variaram de 6,80 a 7,94 e de 7,45 a 8,22, respectivamente. Já na Etapa 2, a variação foi de 6,84 a 7,48, para os valores do dejeto suíno bruto (afluente), e de 7,37 a 7,88, na saída do reator UASB (Figura 3).

Verificou-se que nas duas etapas operacionais houve aumento dos valores de $\mathrm{pH}$, da entrada do afluente até sua saída do reator UASB, certamente em razão da geração de alcalinidade no processo de amonificação e do processo anaeróbio de remoção de matéria orgânica, que, quando em equilíbrio, também tende a elevar o pH em razão do consumo de ácidos voláteis.

A operação de reatores UASB é recomendada em uma faixa de $\mathrm{pH}$ entre 6,5 e 8,2 (CAMPOS, 1999), o que ocorreu durante toda a Etapa 2 e na maior parte da Etapa 1. Já Chernicharo (2008) cita uma faixa ótima de $\mathrm{pH}($ de 6,6 a 7,4)

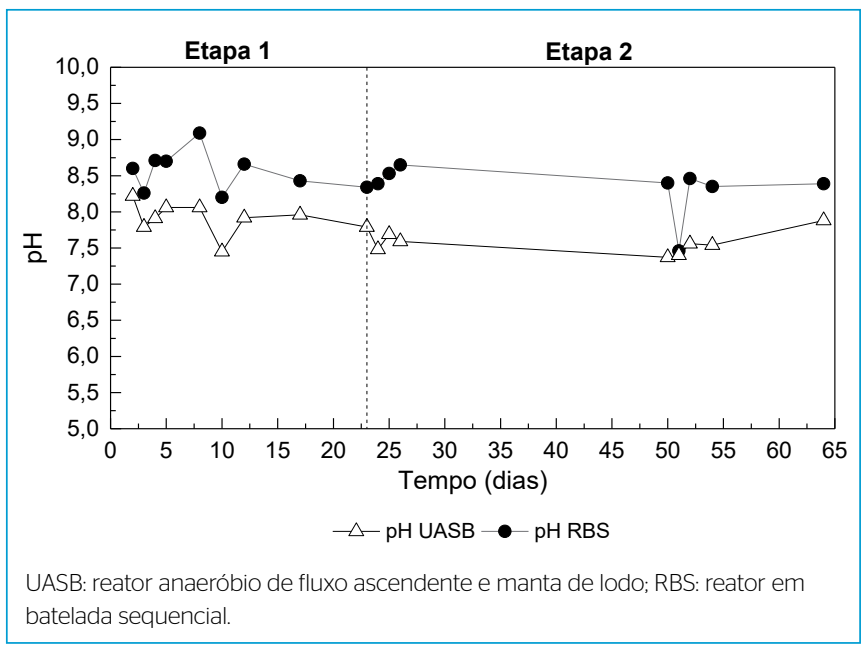

Figura 3 - Comportamento do pH no efluente dos reatores durante a operação do sistema. para o desenvolvimento das arqueias metanogênicas, e segundo Abreu Neto e Oliveira (2009), esse parâmetro não deve ser inferior a 6,2, uma vez que baixos valores de $\mathrm{pH}$ estão associados a altas concentrações de ácidos graxos voláteis e, consequentemente, à falência do processo.

A faixa de $\mathrm{pH}$ entre 7 e 9 é considerada ótima para a ocorrência de nitrificação (ZOPPAS; BERNARDES; MENEGUZZI, 2016) - para valores a partir de 11, segundo Von Sperling (2014), praticamente toda amônia apresenta-se em sua forma livre $\left(\mathrm{NH}_{3}\right)$, a qual provoca inibição das bactérias oxidadoras de amônia. Em contrapartida, outro inibidor do processo é gerado com valores de $\mathrm{pH}$ abaixo de 6,8: o $\mathrm{HNO}_{2}$ (YANG et al., 2016). Diante disso, afirma-se que não houve ação inibitória sobre as bactérias nitrificantes ao longo da operação do RBS, uma vez que o efluente apresentou pH de 8,20 a 9,09 e de 8,35 a 8,65, respectivamente, para as etapas 1 e 2 , dentro do intervalo recomendado, ou ligeiramente acima em algumas oportunidades (Figura 3).

$\mathrm{O}$ pH no efluente do RBS também atendeu aos valores recomendados para remoção de matéria carbonácea (6 a 9) (METCALF; EDDY, 2016) e remoção biológica de $\mathrm{P}$ (maior que 7,25) (OEHMEN et al., 2007). Além disso, embora esses valores tenham se apresentado acima da faixa ótima para as bactérias desnitrificantes (6,5 a 7,5), citada por Metcalf e Eddy (2016), não se observou prejuízo ao processo de desnitrificação.

Com relação à AT, no reator UASB, os valores médios no afluente e no efluente foram, respectivamente, 2.326 e $1.729 \mathrm{mg} \cdot \mathrm{CaCO}_{3} \cdot \mathrm{L}^{-1}$ durante a Etapa 1, e 933 e 1.185 mg. $\mathrm{CaCO}_{3} \cdot \mathrm{L}^{-1}$ na Etapa 2 (Tabela 4). Já para AP (Tabela 4), houve

Tabela 4 - Valores médios de alcalinidade total, alcalinidade parcial, alcalinidade intermediária e alcalinidade intermediária/alcalinidade parcial.

\begin{tabular}{|c|c|c|c|}
\hline \multicolumn{2}{|c|}{ Parâmetros } & Etapa 1 & Etapa 2 \\
\hline \multirow{6}{*}{ AT $\left(m g . L^{-1}\right)$} & Dejeto suíno bruto & & $933 \pm 221$ \\
\hline & LAC & $2.326 \pm 299$ & \\
\hline & LBC & $1.817 \pm 835$ & \\
\hline & Ef. UASB & $1.729 \pm 327$ & $1.185 \pm 64$ \\
\hline & Af. RBS & $3.643 \pm 536$ & $3.185 \pm 64$ \\
\hline & Ef. RBS & $1.412 \pm 741$ & $1.178 \pm 128$ \\
\hline \multirow{6}{*}{$\mathrm{AP}\left(\mathrm{mg} \cdot \mathrm{L}^{-1}\right)$} & Dejeto suíno bruto & & $495 \pm 89$ \\
\hline & LAC & $1.237 \pm 181$ & \\
\hline & LBC & $1.048 \pm 396$ & \\
\hline & Ef. UASB & $1.552 \pm 456$ & $1.034 \pm 88$ \\
\hline & Af. RBS & $3.125 \pm 393$ & $3.034 \pm 88$ \\
\hline & Ef. RBS & $1.330 \pm 692$ & $1.126 \pm 131$ \\
\hline \multirow{6}{*}{$\mathrm{Al}\left(\mathrm{mg} \cdot \mathrm{L}^{-1}\right)$} & Dejeto suíno bruto & & $438 \pm 167$ \\
\hline & LAC & $1.089 \pm 137$ & \\
\hline & LBC & $769 \pm 442$ & \\
\hline & Ef. UASB & $176 \pm 155$ & $151 \pm 73$ \\
\hline & Af. RBS & $518 \pm 226$ & $151 \pm 73$ \\
\hline & Ef. RBS & $82 \pm 57$ & $52 \pm 26$ \\
\hline $\mathrm{Al} / \mathrm{AP}$ & Ef. UASB & 0,11 & 0,15 \\
\hline
\end{tabular}

AT: alcalinidade total; AP: alcalinidade parcial; Al: alcalinidade intermediária; LAC: líquido de alta concentração; LBC: líquido de baixa concentração; Ef:: efluente UASB: reator anaeróbio de fluxo ascendente e manta de lodo; Af: afluente; RBS: reator em batelada sequencial. 
aumento dos valores médios da entrada para a saída do reator UASB, de 1.237 para $1.552 \mathrm{mg} . \mathrm{CaCO}_{3} \cdot \mathrm{L}^{-1}$ e de 495 para $1.034 \mathrm{mg} \cdot \mathrm{CaCO}_{3} \cdot \mathrm{L}^{-1}$ durante as etapas 1 e 2 , respectivamente, proporcionando melhor capacidade de tamponamento do reator. Em razão do consumo dos ácidos graxos de cadeia curta, a AI teve concentrações médias reduzidas de $913 \mathrm{mg} . \mathrm{L}^{-1}$, na primeira etapa, e $287 \mathrm{mg} . \mathrm{L}^{-1}$, na segunda (Tabela 4).

Diante disso, e com os valores médios de $\mathrm{N}$ amonificado, observa-se que houve geração de AP com relação de 11,11 e 5,96 mg.CaCO $\left(\mathrm{mg} \cdot \mathrm{N}_{\mathrm{amon}}\right)^{-1}$ nas duas etapas estudadas, sendo maiores que a relação apresentada por Van Haandel e Marais (1999), de 3,57 mg.CaCO $3\left(\mathrm{mg}_{\mathrm{amon}}\right)^{-1}$.

As relações AI/AP no efluente do reator UASB foram, em média, de 0,11 e 0,15 nas etapas 1 e 2 , respectivamente. Os valores foram inferiores a 0,3 , tido como limite máximo para que ocorra equilíbrio entre a acetogênese e a metanogênese, em que valores superiores indicam a ocorrência de instabilidade no processo anaeróbio (RIPLEY; BOYLE; CONVERSE, 1986).

Por meio da Tabela 4, verifica-se que houve consumo de AT, AP e AI no RBS durante as duas etapas estudadas. Levando em consideração que estequiometricamente o processo de amonificação gera $3,57 \mathrm{mg} \cdot \mathrm{CaCO}_{3}$ para cada $\mathrm{mg}$ de $\mathrm{N}$ amonificado, a nitrificação consome 7,14 mg. $\mathrm{CaCO}_{3}$ para cada mg de $\mathrm{N}$ oxidado, e na desnitrificação há nova produção de $3,57 \mathrm{mg} \cdot \mathrm{CaCO}_{3}$ para cada mg de nitrato reduzido (VAN HAANDEL; MARAIS, 1999). A tendência era de consumo médio $1.018,16$ e 1.011,46 mg. $\mathrm{CaCO}_{3} \cdot \mathrm{L}^{-1}$, respectivamente, nas etapas 1 e 2. Porém, o consumo médio de alcalinidade observado foi maior: 1.795 e $1.908 \mathrm{mg} \cdot \mathrm{CaCO}_{3} \cdot \mathrm{L}^{-1}$, respectivamente.

Diante disso, é possível observar que a adição dos $2.000 \mathrm{mg} . \mathrm{L}^{-1}$ de bicarbonato de sódio ao afluente do RBS se fez primordial, pois certamente a alcalinidade seria um fator limitante para o processo de oxidação do $\mathrm{N}$-amoniacal à nitrato. Outros autores também relataram esse problema de déficit de alcalinidade (DENG et al., 2008; YANG et al., 2016). Em sua pesquisa, por exemplo, Deng et al. (2008) acompanharam o desempenho de um RBS aeróbio como pós-tratamento de um reator UASB tratando dejetos de suinocultura. Em uma de suas condições operacionais, adicionaram 1 g. $\mathrm{L}^{-1}$ de carbonato de sódio ao efluente digerido, obtendo resultados significativamente melhores do que quando tratou o efluente digerido diretamente.

Outro nutriente monitorado na operação do sistema proposto foi o $\mathrm{P}$, sendo observadas, no reator UASB, eficiências médias de remoção nas etapas 1 e 2 de 27 e 12\%, respectivamente, com concentrações efluentes de 33 e $39 \mathrm{mg} \cdot \mathrm{L}^{-1}$ (Figura 2D e Tabela 5). A remoção desse parâmetro em reatores UASB é atribuída à assimilação, à retenção de sólidos no reator e à possibilidade de precipitação química com cálcio ou magnésio (KALYUZHNYI et al., 2000; DENG et al., 2008; DUDA; OLIVEIRA, 2011; SOUZA et al., 2016).

No RBS, a primeira etapa apresentou concentrações médias de $\mathrm{P}$ afluente e efluente de 54 e 18 mg. $\mathrm{L}^{-1}$, respectivamente, com eficiência média de remoção de 59\%, atingindo eficiências de até $88 \%$. Na Etapa 2, houve diminuição na concentração média de $\mathrm{P}$ afluente, que foi de $39 \mathrm{mg} \cdot \mathrm{L}^{-1}$, visto que o reator passou a ser alimentado diretamente com o efluente digerido no reator UASB. Mesmo continuando a adição de fonte exógena de C, registrou-se queda na eficiência média de remoção de $P$ para apenas $43 \%$ nessa segunda etapa, apresentando valor médio efluente de $21 \mathrm{mg} . \mathrm{L}^{-1}$.

As relações $\mathrm{C} / \mathrm{P}$ encontradas com o uso de metanol como fonte externa de $\mathrm{C}$ foram de 14,8 e 29,8 mg.C(mg. $\left.\mathrm{P}_{\text {removido }}\right)^{-1}$, respectivamente, para as etapas 1 e 2. Ressalta-se que os $1.448,3 \mathrm{mg}$ metanol. $\mathrm{L}^{-1}$ adicionados no início da fase
Tabela 5 - Eficiências do reator anaeróbio de fluxo ascendente e manta de lodo, do reator em batelada sequencial e do sistema nas etapas estudadas.

\begin{tabular}{l|c|c|c}
\multirow{4}{*}{ Parâmetros } & \multirow{4}{*}{ Unidade } & \multicolumn{2}{|c}{ Eficiência (\%) } \\
\cline { 2 - 4 } & & Etapa 1 & Etapa 2 \\
\cline { 2 - 4 } & UASB & 84 & 76 \\
\cline { 2 - 4 } & RBS & 58 & 6 \\
\cline { 2 - 4 } & Sistema & 78 & 81 \\
\cline { 2 - 4 } & UASB & 6 & 19 \\
\cline { 2 - 4 } & RBS & 82 & 77 \\
\hline \multirow{4}{*}{ NT } & Sistema & 85 & 81 \\
\cline { 2 - 4 } & UASB & 6 & 19 \\
\cline { 2 - 4 } & RBS & 86 & 92 \\
\hline \multirow{3}{*}{ N-amoniacal } & Sistema & 87 & 99 \\
\cline { 2 - 4 } & RBS & 93 & 99 \\
\hline \multirow{3}{*}{ Fósforo } & Sistema & 95 & 43 \\
\cline { 2 - 4 } & UASB & 27 & 50 \\
\cline { 2 - 4 } & RBS & 59 & 67 \\
\hline
\end{tabular}

DQO: demanda química de oxigênio; NT: nitrogênio total; NTK: nitrogênio total Kjeldahl; N-amoniacal: nitrogênio amoniacal; UASB: reator anaeróbio de fluxo ascendente e manta de lodo; RBS: reator em batelada sequencial.

anóxica do RBS estavam sendo utilizados de forma paralela na desnitrificação e na remoção biológica de P. Logo, não há como quantificar a concentração que estava de fato sendo consumida em cada processo.

Oliveira e Santana (2011) trataram em um RBS efluentes da suinocultura provenientes de dois reatores UASB instalados em série e obtiveram eficiências de remoção de $\mathrm{P}$ de 43 a 66\%, semelhantes às encontradas no presente estudo.

Em termos de eficiência global de remoção de P, obtiveram-se, neste estudo. médias de 67 e 50\%, respectivamente, nas etapas 1 e 2 . Assim como ocorreu no RBS, tais resultados são semelhantes aos alcançados por Oliveira e Santana (2011) em seu sistema de tratamento: 57 a 74\%. Deng et al. (2008) também obtiveram remoções de $\mathrm{P}$ similares (49 a 71\%) no sistema de tratamento com reator UASB e RBS, com maiores concentrações médias de P no afluente (125 mg. $\left.\mathrm{L}^{-1}\right)$, TDH de 3,5 a 4,58 dias e OD de 1,87 a 4,04 mg.. $\mathrm{L}^{-1}$.

A Tabela 5 apresenta um resumo das eficiências do reator UASB, RBS e global, encontradas nas etapas 1 e 2 deste estudo, para os parâmetros avaliados.

O uso da CS melhorou, no sistema como um todo, a remoção de NT e P, como pode ser comprovado pelas eficiências apresentadas na Tabela 5. Dessa forma, o uso dessa unidade antes do reator UASB cumpriu seu objetivo, que era o de fornecer ao RBS um afluente com matéria orgânica facilmente biodegradável em concentrações necessárias para a ocorrência da remoção biológica de $\mathrm{P}$ e da desnitrificação.

\section{CONCLUSÕES}

Durante o estudo, o reator UASB foi operado com TDH de $15,5 \mathrm{~h}$ e COV de 5,5 kg DQO. $\mathrm{m}^{-3} \cdot \mathrm{d}^{-1}$, apresentando, na Etapa 1, quando alimentado com o LAC proveniente da CS, melhor desempenho em relação à etapa posterior 
na remoção de DQO, com eficiência média de $84 \%$. Porém, apesar de a redução da concentração de matéria orgânica apresentar valores compatíveis com os encontrados na literatura, a porcentagem de $\mathrm{N}$ orgânico convertido a $\mathrm{N}$-amoniacal não foi satisfatória: 14 e 56\% para a primeira e segunda etapa, respectivamente.

O pós-tratamento no RBS com o uso do metanol como fonte exógena de $\mathrm{C}$ na fase anóxica (relação $\mathrm{C} / \mathrm{N}$ de 1,1) para remoção biológica de nutrientes, mostrou-se importante. Comparando a primeira etapa com a segunda, houve redução nas eficiências de remoção de DQO (de 58 para 6\%), de NT (de 82 para 77\%) e de $\mathrm{P}$ (de 59 para 43\%). A brusca queda na eficiência de remoção de DQO ocorreu por dois motivos: em razão do arraste de sólidos voláteis para o efluente e pela alimentação do RBS na segunda etapa ter sido realizada apenas com o efluente digerido do reator UASB, em que ocorria a decomposição da fração mais facilmente biodegradável da matéria orgânica.
Com os resultados alcançados nesta pesquisa, o sistema composto de reator anaeróbio tipo UASB e RBS operado em ciclos alternados aeróbio/anóxico, mostrou-se uma alternativa interessante de tratamento biológico de dejetos da suinocultura. A Etapa 1, na qual se utilizou a CS, apresentou o melhor desempenho em termos de eficiência de remoção de NT (85\%) e P (67\%). Porém, a eficiência de remoção de DQO, no valor de 78\%, foi ligeiramente inferior aos $81 \%$ alcançados na Etapa 2.

\section{CONTRIBUIÇÕES DOS AUTORES}

Leite, P. F. A. F.: Conceituação, Investigação, Análise Formal, Metodologia. Vich, D. V.: Supervisão, Metodologia, Escrita - Primeira Redação. Callado, N. H.: Supervisão, Obtenção de Financiamento, Metodologia, Administração do Projeto, Recursos, Escrita — Primeira Redação.

\section{REFERÊNCIAS}

ABREU NETO, M.S.; OLIVEIRA, R.A. Remoção de matéria orgânica, de nutrientes e de coliformes no processo anaeróbio em dois estágios (reator compartimentado seguido de reator UASB) para o tratamento de águas residuárias de suinocultura. Engenharia Agrícola, v. 29, n. 1, p. 148-161, 2009. https://doi.org/101590/S0100-69162009000100015

AMERICAN PUBLIC HEALTH ASSOCIATION (APHA). Standard Methods For Examination of Water and Wastewater. Estados Unidos: American Public Health Association/American Water Works Association/Water Environmental Federation, 2017.

BRASIL. Resolução no 430, de 13 de maio de 2011. Dispõe sobre as condições e padrões de lançamento de efluentes. Brasil: Ministério do Meio ambiente, Conselho Nacional do Meio Ambiente, 2011.

CALLADO, N.H. Reatores seqüenciais em batelada em sistema anaeróbio/ aeróbio tratando esgoto sintético e com remoção de nutrientes. Tese (Doutorado) - Escola de Engenharia de São Carlos, Universidade de São Paulo, São Carlos, 2001

CAMPOS, J.R. Tratamento de Esgotos Sanitários por Processo Anaeróbio e Disposição Controlada no Solo. Rio de Janeiro: Projeto PROSAB, 1999

CHERNICHARO, C.A.L. Pós-tratamento de Efluentes de Reatores Anaeróbios. Belo Horizonte: Projeto PROSAB, 2001.

CHERNICHARO, C.A.L. Reatores Anaeróbios: Princípios do Tratamento Biológico de Águas Residuárias. Belo Horizonte: UFMG, 2008. v. 5.

DENG, L.; CAl, C.; CHEN, Z. The treatment of pig slurry by a full-scale Anaerobic-Adding Raw Wastewater-Intermittent Aeration Process. Biosystems Engineering, v. 98, n. 3, p. 327-334, 2007. https://doi.org/10.1016/j. biosystemseng.2007.08.001

DENG, L.; ZHENG, P.; CHEN, Z.; MAHMOOD, Q. Improvement in posttreatment of digested swine wastewater. Bioresource Technology, v. 99, n. 8, p. 3136-3145, 2008. https://doi.org/10.1016/j.biortech.2007.05.061
DOS SANTOS, M.A.A.; SCHMIDT, V.; BITENCOURT, V.C.; MAROSO, M.T.D Esterqueiras: Avaliação físico-química e microbiológica do dejeto suíno armazenado. Engenharia Agrícola, v. 27, n. 2, p. 537-543, 2007. https://doi org/10.1590/S0100-69162007000300024

DUDA, R.M.; OLIVEIRA, R.A. Tratamento de águas residuárias de suinocultura em reator UASB e filtro anaeróbio em série seguidos de filtro biológico percolador. Engenharia Sanitária e Ambiental, v. 16, n. 1, p. 91-100 2011. https://doi.org/10.1590/S1413-41522011000100013

KALYUZHNYI, S.; SKLYAR, V.; RODRIGUEZ-MARTINEZ, J.; ARCHIPCHENKO, I. BARBOULINA, I.; ORLOVA, O.; EPOV, A.; NEKRASOVA, V.; NOZHEVNIKOVA, A.; KOVALEV, A.; DERIKX, P.; KLAPWIJK, A. Integrated mechanical, biological and physico-chemical treatment of liquid manure streams. Water Science and Technology, v. 41, n. 12, p. 175-182, 2000. https://doi.org/10.2166/ wst.2000.0266

KUNZ, A. Impactos Sobre a Disposição Inadequada de Dejetos de Animais Sobre a Qualidade de Águas Superficiais e Subterrâneas. In: SIMPÓSIO NACIONAL SOBRE USO DA ÁGUA NA AGRICULTURA, 2006. Anais [...]. 2006.

KUNZ, A.; MIELE, M.; STEINMETZ, R.L.R. Advanced swine manure treatment and utilization in Brazil. Bioresource Technology, v. 100, n. 22, p. 5485-5489, 2009. https://doi.org/10.1016/j.biortech.2008.10.039

MACKERETH, F.Y.H.; HERON, J.G.; TALLING, J. Water analysis: some revised methods for limnologists. Freshwater Biological Association Publication, 1978. v. 36.120 p

METCALF, L.; EDDY, H.P. Tratamento de efluentes e recuperação de recursos. 5. ed. Porto Alegre: McGraw Hill, 2016.

NAGARAJAN, D.; KUSMAYADI, A.; YEN, H.; DONG, C.; LEE, D.; CHANG, J.S. Current advances in biological swine wastewater treatment using microalgae-based processes. Bioresource Technology, v. 289, 121718, 2019 https://doi.org/10.1016/j.biortech.2019.121718 
OBAJA, D:; MACÉ, S.; COSTA, J.; SANS, C.; MATA-ALVAREZ, J. Nitrification, denitrification and biological phosphorus removal in piggery wastewater using a sequencing batch reactor. Bioresource Technology, v. 87, n. 1 , p. 103-111, 2003. https://doi.org/10.1016/S0960-8524(02)00229-8

OEHMEN, A.; LEMOS, P.C.; CARVALHO, G.; YUAN, Z.; BLACKALL, L.L.; REIS, M.A.M. Advances in enhanced biological phosphorus removal: From micro to macro scale. Water Research, v. 41, n. 11, p. 2271-2300, 2007. https://doi. org/10.1016/j.watres.2007.02.030

OLIVEIRA, R.A.; FORESTI, E. Balanço de Massa de Reatores Anaeróbios de Fluxo Ascendente com Manta de Lodo (UASB) Tratando Águas Residuárias de Suinocultura. Engenharia Agrícola, v. 24, n. 3, p. 807-820, 2004. https:// doi.org/10.1590/S0100-69162004000300035

OLIVEIRA, R.A.; SANTANA, A.M. Tratamento de águas residuárias de suinocultura em reatores anaeróbios de fluxo ascendente com manta de lodo (uasb) em dois estágios seguidos de reator operado em batelada sequencial (RBS). Engenharia Agrícola, v. 31, n. 1, p. 178-192, 2011. https://doi. org/10.1590/S0100-69162011000100018

RADHAKRISHNAN, M.; GEORGE, S.; SASEENDRAN, P.C.; ANIL, K.S.; USHA, A.P.; KANNAN, A.; ASLAM, M. Efficiency of a developed wastewater treatment model for smallholder swine production systems. The Pharma Innovation, v. 8, n. 4, p. 157-163, 2019.

RAJAGOPAL, R.; ROUSSEAU, P.; BERNET, N.; BÉLINE, F. Combined anaerobic and activated sludge anoxic/oxic treatment for piggery wastewater. Bioresource Technology, v. 102, n. 3, p. 2185-2192, 2011. https://doi. org/10.1016/j.biortech.2010.09.112

RIPLEY, L.E.; BOYLE, W.C.; CONVERSE, J.C. Improved Alkalimetric Monitoring for Anaerobic Digestion of High-Strength Wastes. Journal Water Pollution Control Federation, v. 58, n. 5, p. 406-411, 1986.
SANTOS, L.D.; MAYERLE, S.F.; CAMPOS, L.M.D.S. Tecnologias e sistemas de tratamento para os dejetos da suinocultura. Revista Verde de Agroecologia e Desenvolvimento Sustentável, v. 9, n. 5, p. 12-18, 2014.

SOUZA, C.V.; CAMPOS, A.T.; SOUSA, F.A.; SILVA, E. Tratamento de dejetos líquidos de suínos por meio de lagoas de estabilização visando uso agrícola. Engenharia Ambiental, v. 13, n. 1, p. 107-120, 2016

VAN HAANDEL, A.C.; MARAIS, G. O comportamento do sistema de lodo ativado. Campina Grande: EPGRAF, 1999.

VON SPERLING, M. Introdução à Qualidade das Águas e ao Tratamento de Esgotos. 4. ed. Belo Horizonte: UFMG, 2014

WAKI, M.; YASUDA, T.; FUKUMOTO, Y.; BÉLINE, F.; MAGRI, A. Treatment of swine wastewater in continuous activated sludge systems under di ff erent dissolved oxygen conditions: Reactor operation and evaluation using modelling. Bioresource Technology, v. 250, p. 574-582, 2018. https://doi. org/10.1016/j.biortech.2017.11.078

WANG, S.; DENG, L.; XU, Z.; ZHENG, D.; WANG, L. Acidification during aerobic treatment of digested swine wastewater and its effect on pollutant removal. Chemistry and Ecology, v. 33, n. 5, p. 403-419, 2017. https://doi.org/10.1080/0 2757540.2017.1308502

YANG,D.;DENG, L.;ZHENG, D.;WANG, L.; LIU, Y.Separationof swinewastewater into different concentration fractions and its contribution to combined anaerobic-aerobic process. Journal of Environmental Management, v. 168, p. 87-93, 2016. https://doi.org/10.1016/j.jenvman.2015.11.049

ZOPPAS, F.M.; BERNARDES, A.M.; MENEGUZZI, A. Parâmetros operacionais na remoção biológica de nitrogênio de águas por nitrificação e desnitrificação simultânea. Engenharia Sanitária e Ambiental, v. 21, n. 1 , p. 29-42, 2016. https://doi.org/10.1590/S1413-41520201600100134682 